\title{
The emerging role of clinical audit
}

\author{
Alastair Mason
}

Alastair Mason
FRCP, Associate
Director, Clinical
Effectiveness and
Evaluation Unit,
Royal College of
Physicians
Clin Med JRCPL
2002:2:294-6

\section{Introduction}

Over the last twenty years the NHS has been coming to terms with a plethora of initiatives designed specifically to improve the quality of clinical practice. The names have changed frequently as new groups of management gurus have come up with remixes of old tunes.

One set of activities has been about determining and prescribing what to do and how to do it. Approaches such as evidence-based medicine and getting research into practice have led to the production of clinical protocols, guidelines and standards. Process re-engineering has led to clinical pathways that ensure care is focused or centred on the patient and thus appropriately managed.

Other initiatives have been concerned with reviewing what went on. Medical audit rapidly metamorphosed into clinical audit. Indicators have been developed to measure and assess clinical performance, some of which are related to health outcomes. External benchmarking has been introduced so that local activity can be compared with that elsewhere.

Until recently, these initiatives were being implemented piecemeal without an overarching methodology. This has now been corrected by the mechanisms described in A first class service: quality in the new $N H S^{1}$. Underlying an integrated approach to the improvement of clinical care are a number of basic processes, shown in Box 1, that have now been brought together within the national service frameworks and are being implemented by the clinical governance approach.

Box 1. Processes underlying an integrated approach to improving care.

- Obtain evidence about effectiveness of interventions and processes

- Develop guidelines for who is treated and how

- Set standards to be achieved within a timetable

- Develop and produce process and outcome measures

- Provide opportunities to compare results

- Use results to change clinical behaviour by different means:

- professional and supportive, such as clinical audit run by College

- professional and regulatory, such as service accreditation by a College

- managerial and supportive, such as Clinical Governance Support Team

- managerial and regulatory, such as Commission for Health Improvement
Thus, involvement in clinical audit is now compulsory, involving all health professionals. It is no longer solely an educational pursuit but, through clinical governance, a mainstream part of management. In addition to local studies, clinicians are expected to audit nationally chosen topics laid out in the service frameworks that involve comparisons with other places.

The progression from the first mention of reviews of clinical practice, to the 1960/1970s (cogwheel) reports of the joint working party on the organisation of medical work in hospitals ${ }^{2}$, to the present day has been a triumph of pragmatism and opportunism. Although coherent theories of how best to evaluate care have been around for a long time, actual practice has been determined mainly by the tension between a profession fighting a rearguard action to keep these matters professional, and politicians and senior NHS managers bent on taking a central role in the review process.

\section{Local audits}

Most experience of clinical audit has been at NHS trust level before it became an integral part of the clinical governance processes. Although considerable sums of money have been spent, initially ring-fenced solely for the purpose, results in terms of improvements in care have been limited.

Before the introduction of clinical governance, trust managers did not perceive clinical audit as an important function impinging on their politically set agenda. Clinicians reinforced this view by keeping activities under wraps as part of postgraduate educational activities. Few managers knew what areas of work had been audited, let alone any results of the projects. The low managerial priority given to clinical audit in many trusts led to under-resourcing of activities particularly with respect to computing and expert technical advice. Earmarked audit funds were not infrequently raided for other purposes.

Local audit projects have been small scale, frequently picking relatively unimportant areas of uncommon clinical work. Technical expertise in designing valid studies was rare and all too often projects were invalid in that the number of patients was inadequate to produce statistically significant results. The design of data collection proforma, the 
assurance of data quality and interpretation of statistical results were also commonly amateur and low standard.

There is little evidence to show that clinical audit has changed clinical practice and led to better health outcome. Results of studies appeared months after projects began and with rapid staff turnover new health professionals felt that the results did not apply to them. As results were retained within individual units, poor performance was kept secret and there was no external pressure to encourage the requisite improvements. Where changes were made, the audit loop was rarely closed by a repeat audit to monitor whether they had led to better outcomes. Even when action had been successfully taken, old bad habits frequently returned when there was no reinforcement.

Above all, the local approach meant that trusts had no idea how their practice compared with others and thus what results were possible in the best units.

\section{National audits}

The future of clinical audit, as a major agent of change, lies with nationally organised projects associated with national priorities, determined in documents such as the service frameworks. The Clinical Evaluation and Effectiveness Unit (CEEu) at the Royal College of Physicians has been at the forefront of developing such comparative audits. Three major clinical areas have already been addressed - stroke, prescribing for elderly people and most recently acute myocardial infarction. Important advances have been made in the methodology of audit, particularly with respect to electronic data capture and transfer, information security and confidentiality and the use of comparative information to improve clinical practice.

The methodologies used by CEEu for the three clinical audit areas have become more sophisticated as the technology available has improved.

In 1998 the CEEu was commissioned by the Department of Health to perform a national sentinel audit of stroke care ${ }^{3}$. Over 200 trusts, comprising more than $80 \%$ of hospitals admitting stroke patients, agreed to take part and submitted data on 7,000 patients. The data were collected locally onto forms that could be computer read using text recognition software. Once the data had been returned to $\mathrm{CEEu}$, it was possible to check them, analyse results and return a detailed report to participants within three months.

In 1999, the Unit commenced a second sentinel audit that used a different approach to data collection. The project about evidence-based prescribing for older people ${ }^{4}$ included a simple floppy disc based algorithm that helped to prompt the appropriate data collection on the wards, in primary care and in nursing homes. Because drugs may be over- or under-used, the algorithms were designed not just to collect what was prescribed, but also to assess whether the scripts were appropriate. By using this 'intelligent' questionnaire, the data were returned to the CEEu as well as being available immediately for local teams to do their own analyses. The project collected over 15,000 patient records from 141 centres.

The most recent development has been to use Internet tech- nology. The Myocardial Infarction National Audit Project (MINAP) has based its data collection on the methods of the Central Cardiac Audit Database (CCAD) that has tackled and solved many of the complex technological and security issues relating to automatic data transfer. Each hospital must have at least a personal computer on which to site the data collection tool, and there is a secure link that transmits data to the central computer in encoded form.

There is a further feature that will be essential for future audits. The MINAP project requires a unique patient identifier but also has to conform to the legitimate demands of privacy and confidentiality. To meet these requirements, the NHS number is encrypted at unit level using a local code before the data are encrypted again for transfer. On the central server, those analysing the data can only view the encrypted NHS number and thus cannot relate any data to individuals.

However, when the local team log in to the server, using their own code, they can view the uncoded identifiers in just the same way as if they were performing an internal audit study. Clinicians can submit data on one day and by the next can obtain up-to-date comparative information about their performance.

The CCAD system also has the ability to separate the coded NHS identifiers from the files, decode them and transmit the list of numbers to the computer at the Office for National Statistics. Details of the alive/dead status of each case are returned and entered in the full records in the database without the need for human intervention.

Information derived from comparative audits can be used, as shown in Box 1, in a number of different ways. Indicators derived from audits may be included in the national performance assessment framework. The Commission for Health Improvement will be a major user wishing, in its managerial regulatory role, to know whether NHS trusts have taken part in audits and how they performed. Questions are already being asked in visits to trusts about participation in the CEEu stroke audit.

The Clinical Governance Support Team, set up as part of the Modernisation Agency to support trusts, will also find such information invaluable and have been using data from the stroke audit in their training programmes.

Royal Colleges may use the results in a regulatory or supportive way. Many colleges insist on audit participation as a factor in the approval of posts for training or the accreditation of a particular service. However, the Royal College of Physicians, through the $\mathrm{CEEu}$, has also pioneered a supportive approach to achieving improvements in clinical practice with the stroke audit.

Rapid feedback to audit participants in a way that can be easily understood is critical. The stroke project fed back data within three months of completing the data collection exercise. Results were presented both by numerical tables containing the detail but also by the simple expedient of box plots in which the local performance is set out against the national picture expressed in terms of quartiles ${ }^{5}$. A position in the bottom quartile implies that the data were inadequate, the resources to 
deliver the care were inadequate or that the clinicians were of poor quality. Similar presentation techniques can be used to benchmark performance for other clinical conditions ${ }^{6}$.

Active feedback to participants is also essential. Seventeen meetings for 50-100 clinical staff of all disciplines in each of the 'old' regions of England, Wales and Northern Ireland were run to disseminate the stroke audit information. The local stroke teams understood and took ownership of their results that showed that the organisation of care was an important predictor of the processes of care within a unit ${ }^{7}$. In some hospitals, managers used the data to improve services that had been of concern for some time but for which there had previously been no information to justify management action.

The audit cycle must be completed by follow-up audits. The re-audit of stroke care showed improvements in the organisation and the process of care in each and every region in the country. The few health outcomes measured also moved in the same direction ${ }^{8}$.

\section{Conclusion}

Clinical audit, after a chequered progression, now has a coherent and sustainable underpinning, is increasingly associated with clinical policy and now forms part of the local clinical governance arrangements. However, major nationwide improvements in care will only come from professionally led national audits using all the benefits of information technology.

The Royal College of Physicians, through the work of the $\mathrm{CEEu}$, has been a prime mover in developing the requisite methodologies, and the experience of the Unit has also shown that audit results, rapidly and actively fed back to participants, lead to improvements in the organisation, process and outcomes of clinical care.

\section{References}

1 Department of Health. A first class service; quality in the new NHS. London: DH, 1998.

2 Department of Health and Social Security. Third Report of the Joint Working Party on the Organisation of Medical Work in Hospitals. London: HMSO, 1974.

3 Rudd AG, Irwin P, Rutledge Z, Lowe D et al. The national sentinel audit of stroke a tool for raising standards of care. J Roy Coll Phys Lond 1999; 33:460-5.

4 Grant RL, Batty GM, Aggarwal R, Lowe D et al.. National sentinel clinical audit of evidence-based prescribing for older people: methodology and development. J Eval Clin Pract 2002;8:189-98.

5 Pearson MG. National comparative audits: lessons from stroke and myocardial infarction. J Clin Excellence 2001;3:3-9.

6 Bucknall CE, Ryland I, Cooper A, Coutts I et al. National benchmarking as a support system for clinical governance. J Roy Coll Phys Lond 2000; 34:52-6.

7 Rudd AG, Irwin P, Rutledge Z, Lowe D, Pearson MG. Regional variations in stroke care in England, Wales and Northern Ireland. Results from the national sentinel audit of stroke. Clin Rehab 2001;15:562-72.

8 Rudd AG, Lowe D, Irwin P, Rutledge Z, Pearson MG. National stroke audit: a tool for change? Quality in Health Care 2001;10:141-51. 